\title{
Influence of operational variables in a hydrodynamic bearing on the generation of Acoustic Emission
}

\author{
S. A. Mirhadizadeh, E.P. Moncholi, D .Mba,
}

\begin{abstract}
Detecting mechanical faults of rotating machines particularly in hydrodynamic bearings has been recognised as important for preventing sudden shut downs. This technical note presents an experimental investigation that is aimed at understanding the influence of operational variables (speed, load, etc) on generation of Acoustic Emission in a hydrodynamic bearing. It is concluded that the power losses of the bearing are directly correlated with Acoustic Emission levels.
\end{abstract}

Keywords: Acoustic Emission, hydrodynamic, bearing, condition monitoring

\section{Introduction}

The traditional definition of Acoustic Emission (AE) is an elastic wave produced as a result of swift discharge of energy from a source within a material that is compelled by an externally applied stimulus [1]. The first comprehensive investigation into the phenomenon of AE was undertaken by Kaiser in 1950 [2]. Kaiser was the first to digitally acquire AE signals produced in the crystal structure of materials during stress tests. The AE technology is continually developing into a complimentary technology for condition monitoring of machines [3] where most investigators applications have utilised the frictional phenomenon associated with AE. Acoustic Emission technology has advantages in comparison to other diagnostic methods [4]. Firstly, defects are easier to detect because of improved signal to noise ratio and secondly, since it can detect mechanical abnormalities at high frequencies, it is far more sensitive in comparison to vibration techniques. In addition Acoustic Emission is non-intrusive and is applicable on any type of machinery regardless of speed. Through it must be stated that the application of AE technology does have its limitations [5]. In the application of AE to hydrodynamic bearings (journal bearings) Sato [6] was the first investigator that directly addressed monitoring the integrity of such bearings. Typical problems that are associated with journal bearings include 
wear and metal wipe which is a direct consequence of the shaft making contact with the journal, such frictional contact is a prime source of AE. Other sources of $\mathrm{AE}$ associated with rotating machines include impacting, cyclic fatigue, friction, turbulence, material loss, cavitations, leakage, etc [3]. Others [7-11] have applied the AE technology to shaft-seal rubbing in large power generation turbines. Leahy [12] undertook the most realistic controlled verification of applicability of AE to shaft seal rubbing where it was noted that a simulated rub on the shaft of an operating steam turbine could be detected with $\mathrm{AE}$ sensors mounted on the bearing pedestal. Al-Shaikh Mubarak [13] attempted to apply the technology for monitoring blade rubbing. Whilst in all the cases highlighted above the measurement of $\mathrm{AE}$ was taken at the journal bearing housing no attempt was made to understand the factors that govern the generation of $\mathrm{AE}$ within the bearing, particularly as the operational variables such as load, film thickness, and speed change with operating requirements.

The aim of this investigation was to ascertain the relationship between rotational speed, applied load, theoretical film thickness, power losses, shear stress and AE for a hydrodynamic bearing, which hitherto has not been explored.

\section{EXPERIMENTAL PROGRAMME}

The hydrodynamic bearing test rig employed for this study has an operational speed range between $10 \mathrm{rpm}$ to $5000 \mathrm{rpm}$ with a maximum load capability of $20 \mathrm{kN}$. Figure 1 depicts the test rig employed for this investigation.

In developing an understanding of the relationship between Acoustic Emission and the operational variables an experimental programme was developed which involved testing at a speed range of between 750 to $4500 \mathrm{rpm}$ and a load range of between $2 \mathrm{KN}$ to $10 \mathrm{KN}$. The hydrodynamic bearing material was Bronze. The test bearing had a radius of $40 \mathrm{~mm}$, length of $80 \mathrm{~mm}$ and a measured radial clearance of $0.17 \mathrm{~mm}$. 


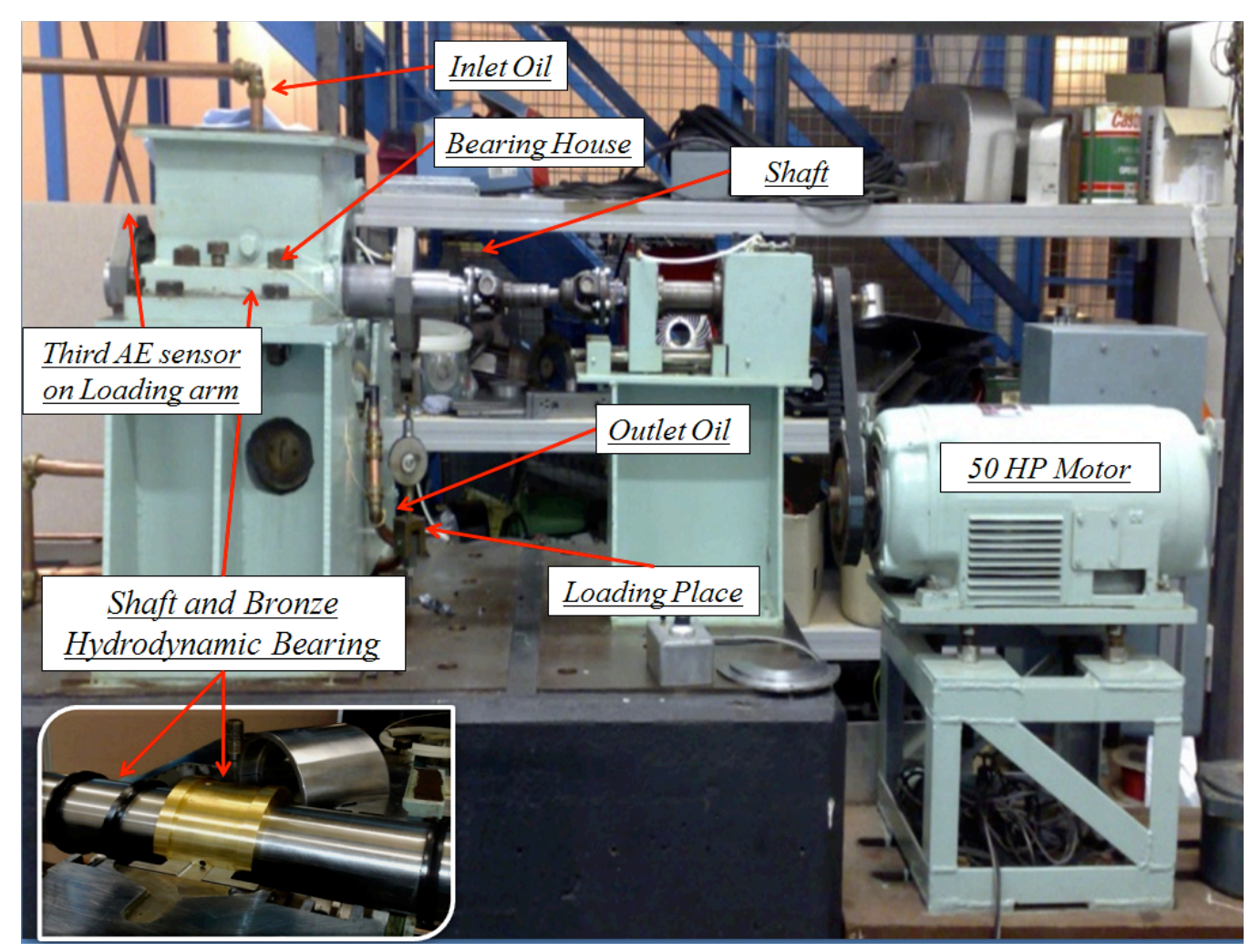

\section{Figure 1 Test rig layout}

To understand the influence of viscosity on generating $\mathrm{AE}$, three different oil types were employed. This included:

Alpha SP68, kinematic viscosity $68 \mathrm{cSt}$ and $8.53 \mathrm{cSt}$ at $40^{\circ} \mathrm{C}$ and $100^{\circ} \mathrm{C}$ of respectively

$>$ Alpha SP220, kinematic viscosity $220 \mathrm{cSt}$ and $18.7 \mathrm{cSt}$ at $40^{\circ} \mathrm{C}$ and $100^{\circ} \mathrm{C}$ of respectively

Alpha SP460, kinematic viscosity $460 \mathrm{cSt}$ and $30.5 \mathrm{cSt}$ at $40^{\circ} \mathrm{C}$ and $100^{\circ} \mathrm{C}$ of respectively

Two Physical Acoustics WD type sensors with a frequency bandwidth of between $100 \mathrm{KHz}$ to $750 \mathrm{KHz}$ were employed. Both sensors were placed directly onto the test bearing at each axial end (see figure 2) and connected to a pre-amplifier at 40dB gain. A third WD sensor was placed on the loading arm, see figure 1. For all tests undertaken in this investigation the AE r.m.s values were recorded over a time constant of $10 \mathrm{msec}$ and a sampling rate of $100 \mathrm{~Hz}$. In addition, four Jtype thermocouples were fixed on the axial end at the bearing in the loaded zone, and one K-type thermocouple was placed in the oil bath, see figure 2 .The thermocouples had an operating range 
of 0 to $200^{\circ} \mathrm{C}$ with an accuracy of $\pm 1.5^{\circ} \mathrm{C}$. Measurements of temperature were taken throughout all test conditions at a sampling rate of $10 \mathrm{kHz}$.

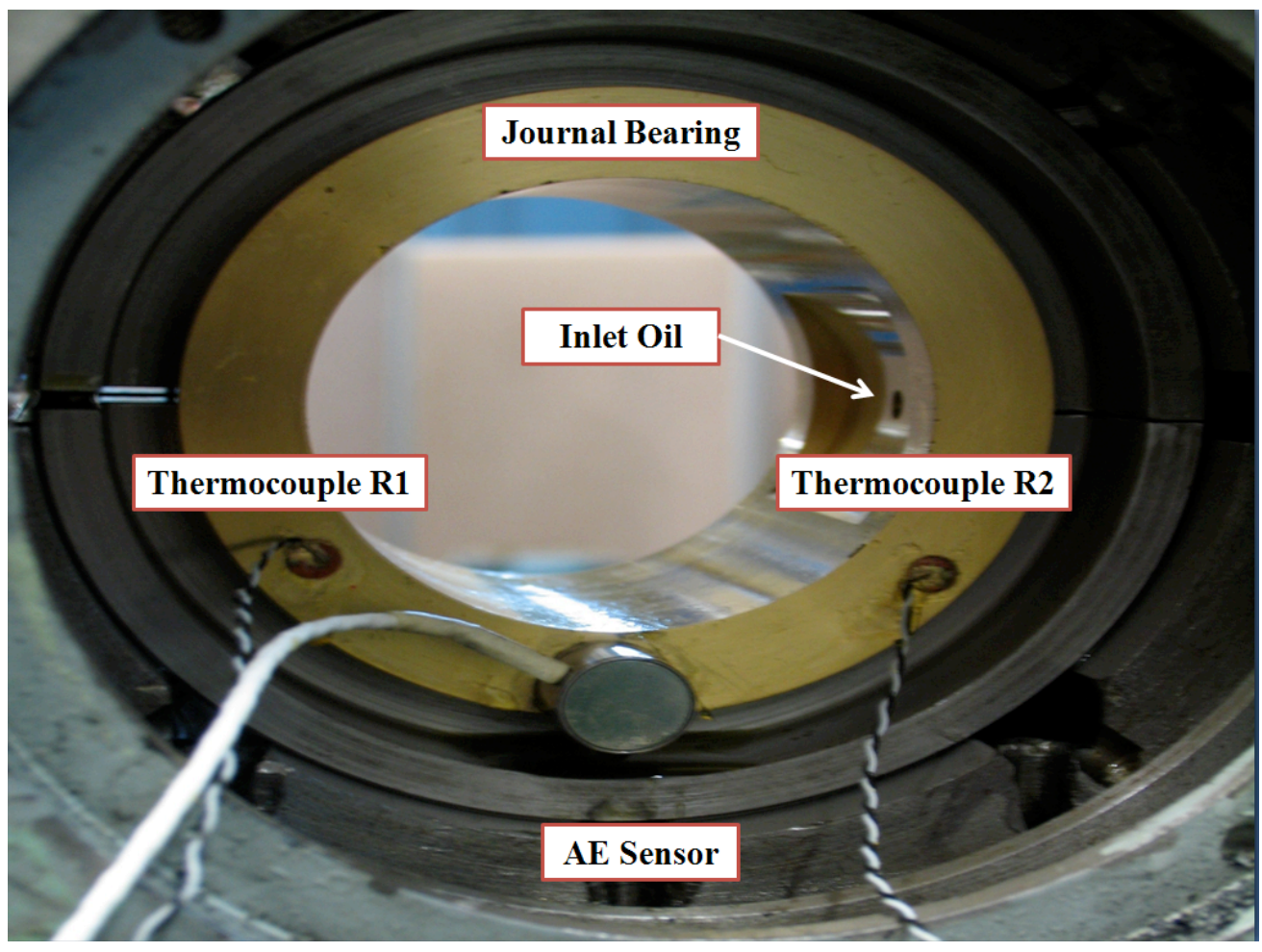

Figure 2 Location of $\mathrm{AE}$ and thermocouple sensors on test bearing

This investigation involved varying the bearing rotational speed for fixed loads and also investigating the influence of different viscosities whilst recording the AE r.m.s levels. Prior to performing the tests, the temperature of the test bearing was raised to approximately $40^{\circ} \mathrm{C}$; this was achieved by running the test-rig in excess of $1000 \mathrm{rpm}$ at $1 \mathrm{KN}$. As soon as the desired temperature was reached, the test sequence began.

The tests conditions investigated included five rotational speeds (750rpm, 1500rpm, 2500rpm, 3500rpm and 4500rpm) three oil types (SP68, SP220 and SP460) and three load conditions, $(2 \mathrm{KN}, 6 \mathrm{KN}, 10 \mathrm{KN})$. Load on the test hydrodynamic bearing was achieved with two hydraulic 
mechanisms either side of the test bearing. Two hydraulic cylinders were connected to two loading bearings (ball bearing) which were fixed on the shaft either side of the hydrodynamic test bearing. These were placed either side of the test bearing to ensure uniform loading along the length of the test bearing. Given that such bearings are known to emit significant AE noise a circumferential groove was cut into the shaft and a "plastic" strip was placed between the inner race of the bearing and the shaft, see figure 3 . This ensured no AE transmission from the rolling element bearings could influence measured AE's from the journal bearing. In addition, the drive motor was connected to the drive shaft via a belt drive thus eliminating AE noise generated from the electric motor.

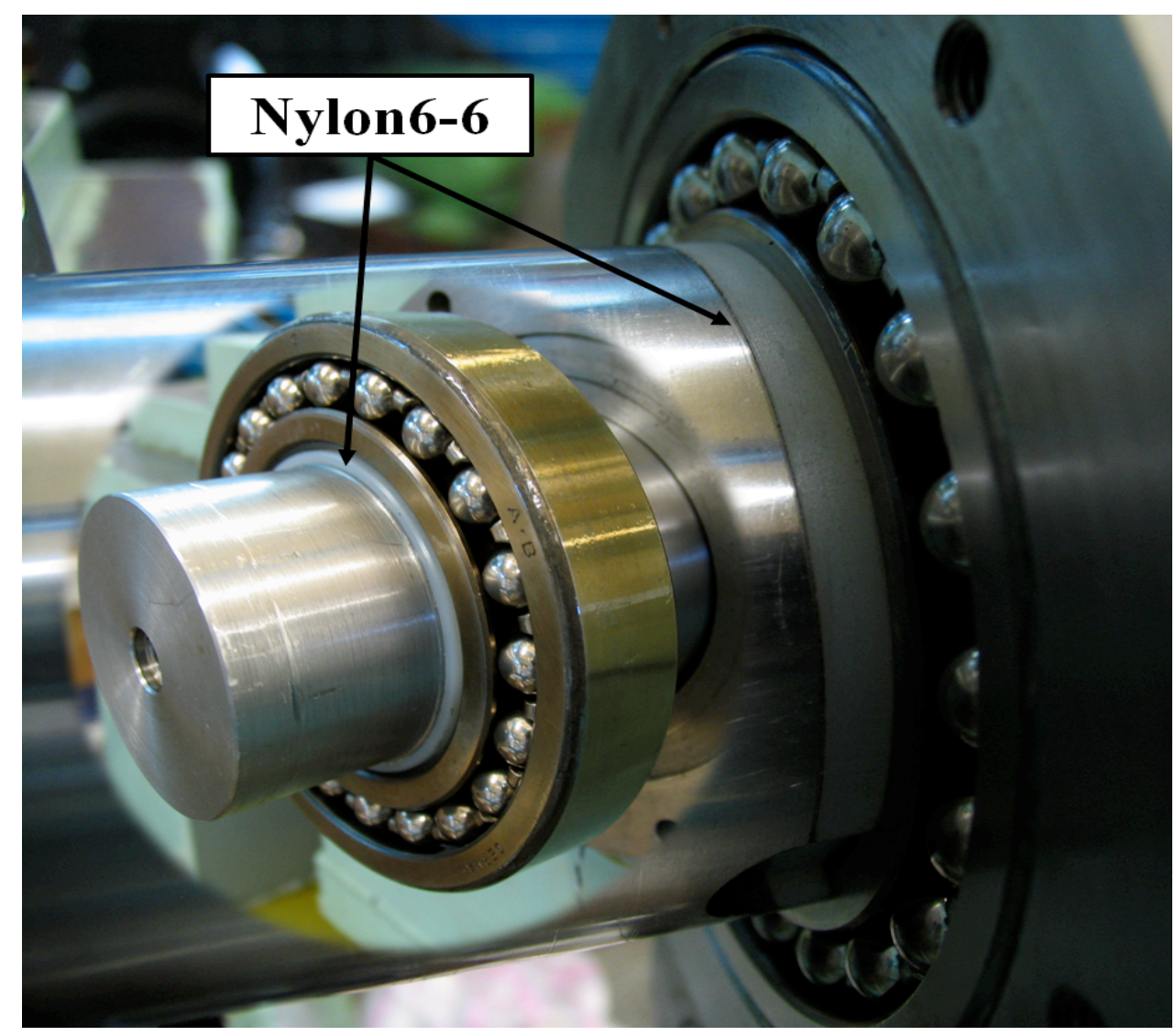

Figure 3 Nylon 6/6 applied to attenuate $\mathrm{AE}$ from the rolling element bearing

Also a coupling was employed between the drive shaft and the shaft from the motor within the test bearing, further eliminating reducing any AE's from outside the test bearing. Attenuation tests were undertaken (Hsu, Nelson) on the test rig at various defined locations, see figure 4 and 
table 1. From the results present it was clear that AE could be transmitted across the plastic strip however attenuation across the strip to test bearing shaft was in the order of $35 \mathrm{~dB}$, this would imply a 55-Fold reduction in AE amplitude levels across the strip. This is of particular significance as all unwanted AE contributors must be eliminated (such as the rolling element bearings onto which load are applied to the shaft). Attenuation test were undertaken with the oil supply to the bearing switched on, i.e, oil was flowing into and out of the bearing.

Acquisition of $\mathrm{AE}$ and temperatures values were acquired continuously over a duration of $10 \mathrm{mins}$ for every speed, viscosity and load condition tested. Values presented, hence forth are averaged over the 10min duration, in addition, standard deviations are also detailed (see table A1, appendix).

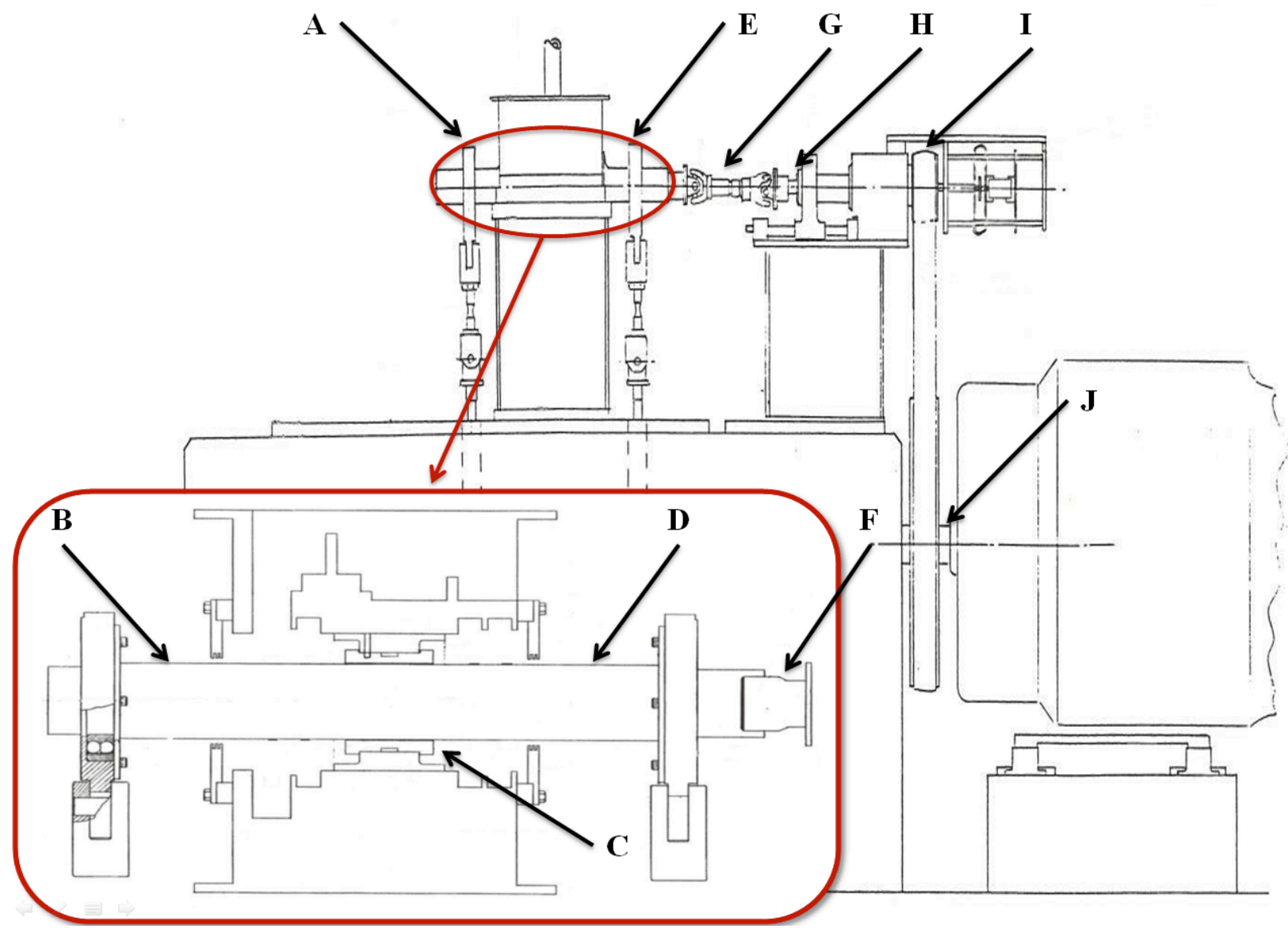

Figure 4 Attenuation tests on the test rig 
Table 1 Attenuation results in Journal Bearing Test Rig

\begin{tabular}{|c|c|c|c|c|c|c|c|c|c|c|}
\hline Attenuation Nelson Breaks & A & B & C & D & E & F & G & H & I & J \\
\hline AE Amplitude Ch1(dB) & 35 & 78 & - & 78 & 78 & 40 & 73 & - & - & - \\
\hline AE Amplitude Ch2(dB) & 43 & 75 & - & - & 75 & 37 & 71 & - & - & - \\
\hline AE Amplitude Ch3(dB) & 78 & 41 & - & - & - & - & - & - & - & - \\
\hline
\end{tabular}

'-' No detectable emission

\section{Experimental Results}

From these results and given attenuation rates already ascertained, measurements of AE on the hydrodynamic bearing will be void of any contributions from the load carrying rolling element bearing. For instance, AE measurements from ch-3 at $4500 \mathrm{rpm}$ were noted at $0.14 \mathrm{~V}_{\text {r.m.s, }}$ given the attenuation across the plastic strip to the sensors on the test bearing, it would be expected that channel's 1 or 2 would recorded AE levels in the order of $0.003 \mathrm{~V}_{\text {r.m.s }}$ on the bearing however AE levels on the test bearing were between 10 to 20 fold higher than $0.003 \mathrm{~V}_{\text {r.m.s }}$, authenticating that measured $\mathrm{AE}$ on the test bearing could be attributed to emissions from the test bearing only. Observation from a typical test sequence is present in figure 5.

The results of all tests undertaken are presented in figure 6 which highlights observations of the theoretical minimum film thickness $\left(\mathrm{h}_{\mathrm{o}}\right)$ and AE r.m.s measured on the test bearing for a fixed load condition with varying dynamic viscosities. All calculations of minimum film thickness and power losses were based on well established procedures [14] with the main influencing factors including the oil kinematic viscosity, operating temperature, bearing geometry, Sommerfield number and shaft eccentricity. The Sommerfield number is a non-dimensional number which is characteristic for a journal bearing in given working conditions. 


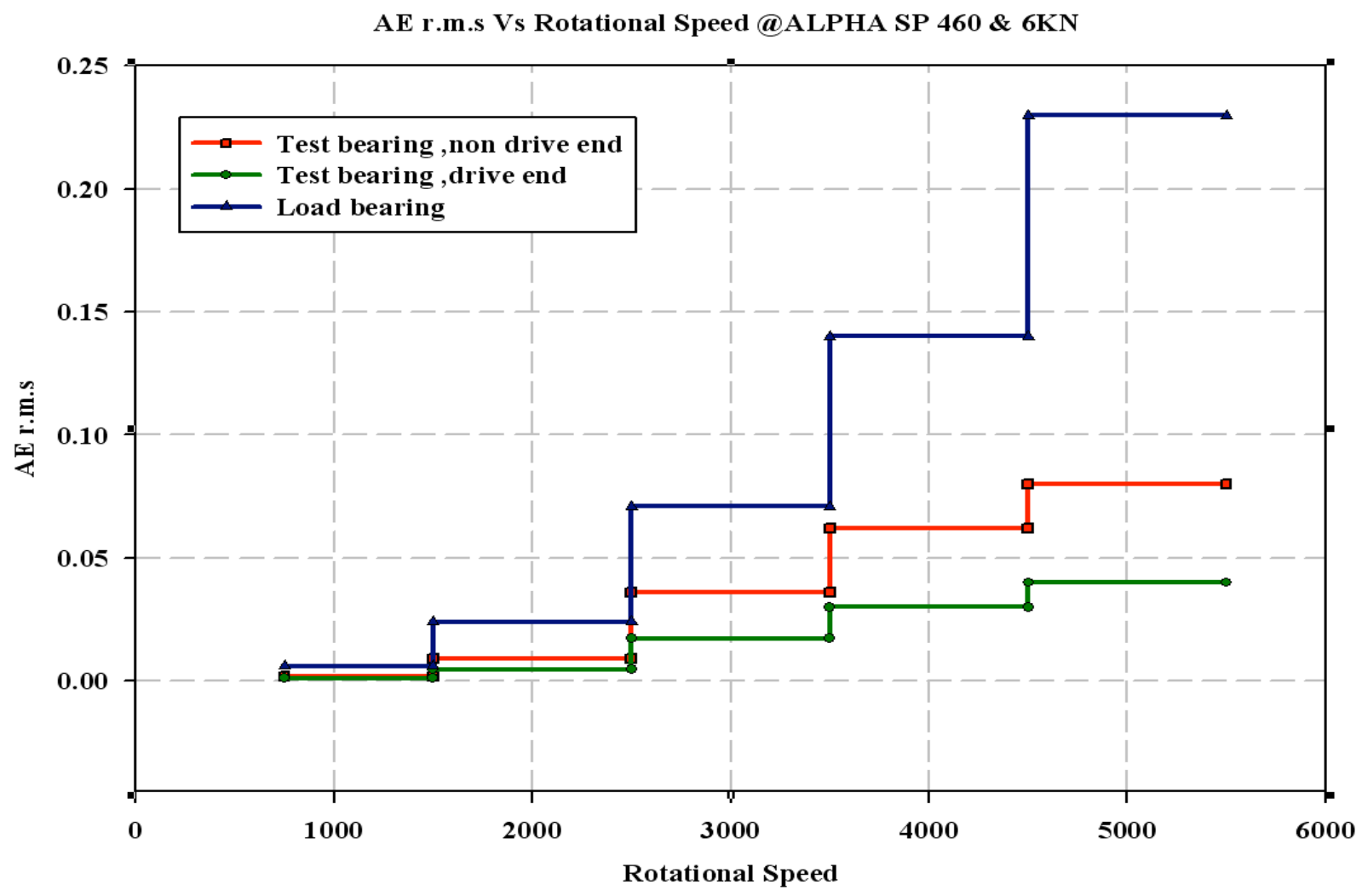

Figure 5 Typical test sequence for a load of 6KN (oil SP460) 


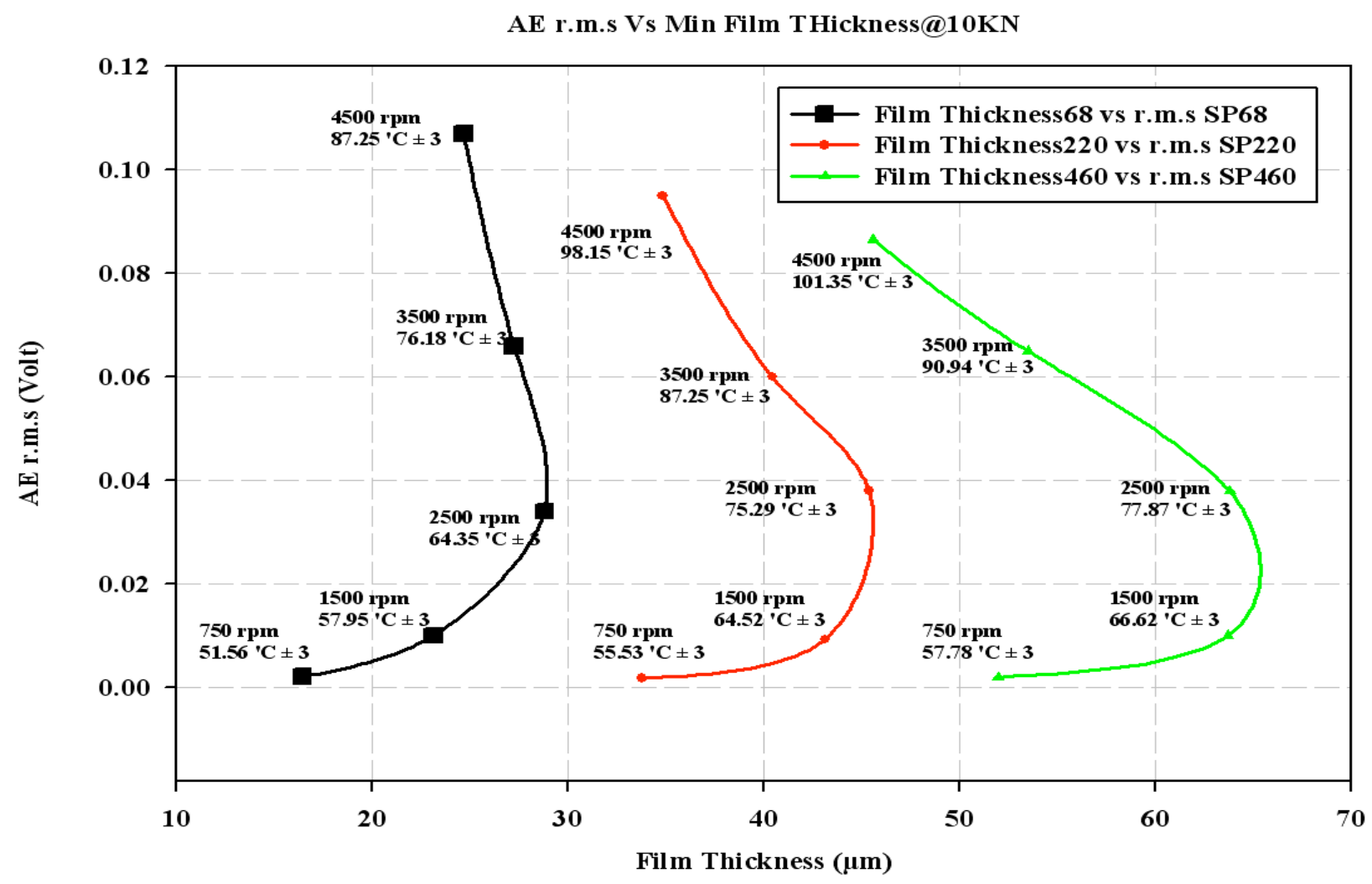

Figure 6 AE r.m.s levels at an applied load 10KN

It was evident that an increase in speed resulted in an increase in measured $\mathrm{AE}$ even though for same test conditions there was a decrease in theoretical film thickness. For instance at a speed of $3500 \mathrm{rpm}$ and a corresponding bearing temperature of $87^{\circ} \mathrm{C}$ the oil film thickness was less than at the lower speed at $2500 \mathrm{rpm}\left(75^{\circ} \mathrm{C}\right)$ due to the reduction in viscosity of the oil. Irrespective of the decrease or increase in theoretical film thickness the levels of $\mathrm{AE}$ increased with increasing rotational speed. Changes in rotational speed resulted in increased AE levels in the order of $200 \%$ on average though the actual predicted change in minimum film thickness with increased speed was of the order of approximately $10 \%$ on average for all test, see table A1(appendix). Standard deviations $(\delta)$ of calculated minimum film thickness values and measured temperature values are detailed in the appendix and the deviations were deemed low and acceptable. As with hydrodynamic bearings, there is no asperity contact and in the author's view the corresponding 
increase in $\mathrm{AE}$ levels is attributed to the friction associated with the shearing effect of the lubricant and associated frictional/power losses. The authors thought it prudent to establish/confirm such a phenomenon.

\section{Hydrodynamic Shear Stress}

The source of $\mathrm{AE}$ in a hydrodynamic bearing, given that under normal operating conditions the hydrodynamic oil film is sufficiently large to ensure no asperity contact, can only be attributed to the friction within the fluid and the friction reaction of the fluid on the shaft. Such friction in fluid is attributed to the shear stress which is defined as the force per unit area exerted by a solid boundary on a fluid in motion in a direction on the local tangent plane [15]. The shear stress for a Newtonian fluid can be expressed as following equation:

$$
\tau_{w}=\mu \frac{\delta u}{\delta y}
$$

$>\mu$ is the dynamic viscosity of the fluid;

$>u$ is the velocity of the fluid along the boundary;

$>y$ is the height of the boundary.

In calculation of shear stress the inner cylinder (shaft) rotates at constant speed and the inner diameter at the bearing bush is assumed stationary. It is also assumed that the oil flow is laminar. To obtain an expression for velocity profile and shear stress distribution a few assumption have been made, including:

1) Steady flow, which eliminates time variations in fluid properties and equations.

2) Temperature profile within the oil film is assumed constant.

3) Incompressible flow, simplifying the governing equations of fluid flow can

4) Periphery symmetric flow

5) No flow or variation of properties in the direction axial 
The relationship between velocity profile, shear stress and film thickness were determined by Rook [16]:

$$
\begin{aligned}
\vartheta_{\theta} & =c_{1} \frac{\mathrm{r}}{2}+\mathrm{c}_{2} \frac{1}{\mathrm{r}} \\
\tau_{r \theta} & =\mu \frac{2 \operatorname{\omega R} \mathrm{R}_{2}}{1-\left(\frac{\mathrm{R}_{1}}{\mathrm{R}_{2}}\right)^{2}} \frac{1}{\mathrm{~h}_{0}{ }^{2}}
\end{aligned}
$$

Where:

$\tau_{r \theta}$-is shear stress distribution in the bearing $\quad \mathrm{R}_{1}$-is shaft radius

$\mu$-is dynamic viscosity $\quad \mathrm{R}_{2}$-is bearing radius

$\omega$-is rotational speed $\quad \mathrm{h}_{0}$-is film thickness

From the equation (3) theoretical estimates of shear stress were determined. Observation of AE r.m.s values for calculated levels of shear stress is shown in figure 7. This shows a steep increase in shear stress levels between 750 to $1500 \mathrm{rpm}$ after which levels remained relatively steady(1500 to $2500 \mathrm{rpm})$. From 2500 to $4500 \mathrm{rpm}$ the levels of shear stress steadily decreased with increase speed. 


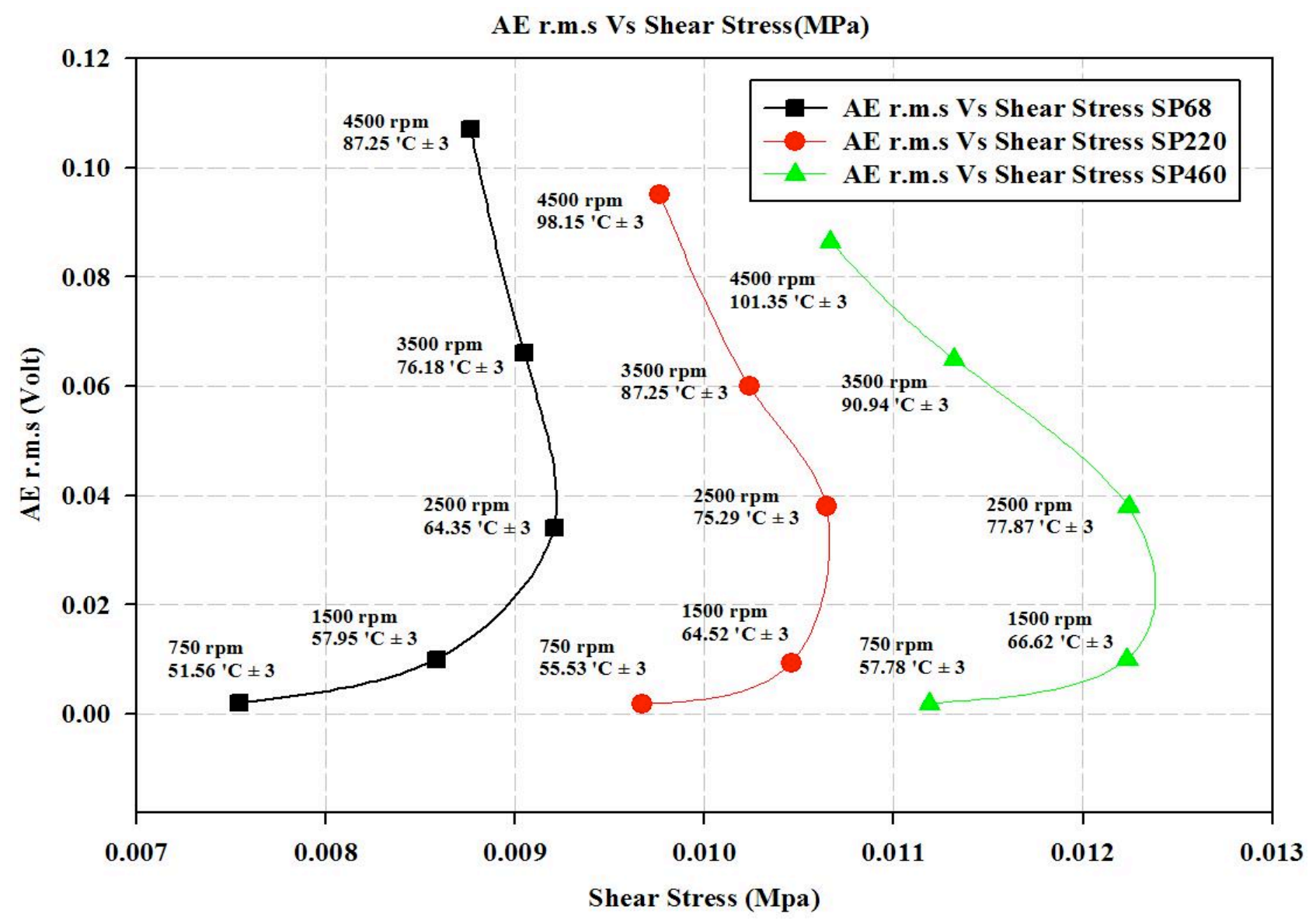

Figure 7 AE r.m.s and shear stresses for varying speed and constant load conditions of $10 \mathrm{KN}$ and different dynamic viscosities

In an attempt to understand the relationship between $\mathrm{AE}$ and shear stress plots showing correlation between shear stress, film thickness and rotational speed are presented in figure 8 . From this figure three regions are detailed, region 'A','B' and 'C'. It is evident that in the region ' $A$ ', an increase in speed resulted in an increase in the theoretical minimum film thicknesses and a corresponding increase in estimated shear stress values. In region 'B', both parameters of dynamic viscosity and rotational speed had a direct influence in reaching shear stress levels and their calculations to shear stress levels are assumed equal. And finally in region ' $\mathrm{C}$ ', were increasing the rotational speed caused increasing the oil temperatures and a reduction in the dynamic viscosity; the theoretical minimum film thicknesses decreased and a corresponding decrease in the estimated shear stress levels was noted. In this region, the most influencing parameter is low viscosity and high rotational speed. 
These relationships are attributed to the fact that the shear stresses increase when the rotational speed increases but the increase in speed causes an increase in oil temperature thereby decreasing the shear stresses as the oil viscosity decreases. The shaded of area in figure 8 shows the range of theoretically determined shear stress and film thickness values based on experimental measurements and the sensor accuracies. In addition, the associated friction factor values are presented in figure 8; the values of which mirror trends in shear stress and film thickness. The friction factor is dimensionless parameter which is determined from the eccentricity ratio and Sommerfeld number of the bearing, and, is employed to calculate the power losses of the bearing [14]. The result presented in figure 8 was similar for all three different viscosities investigated.

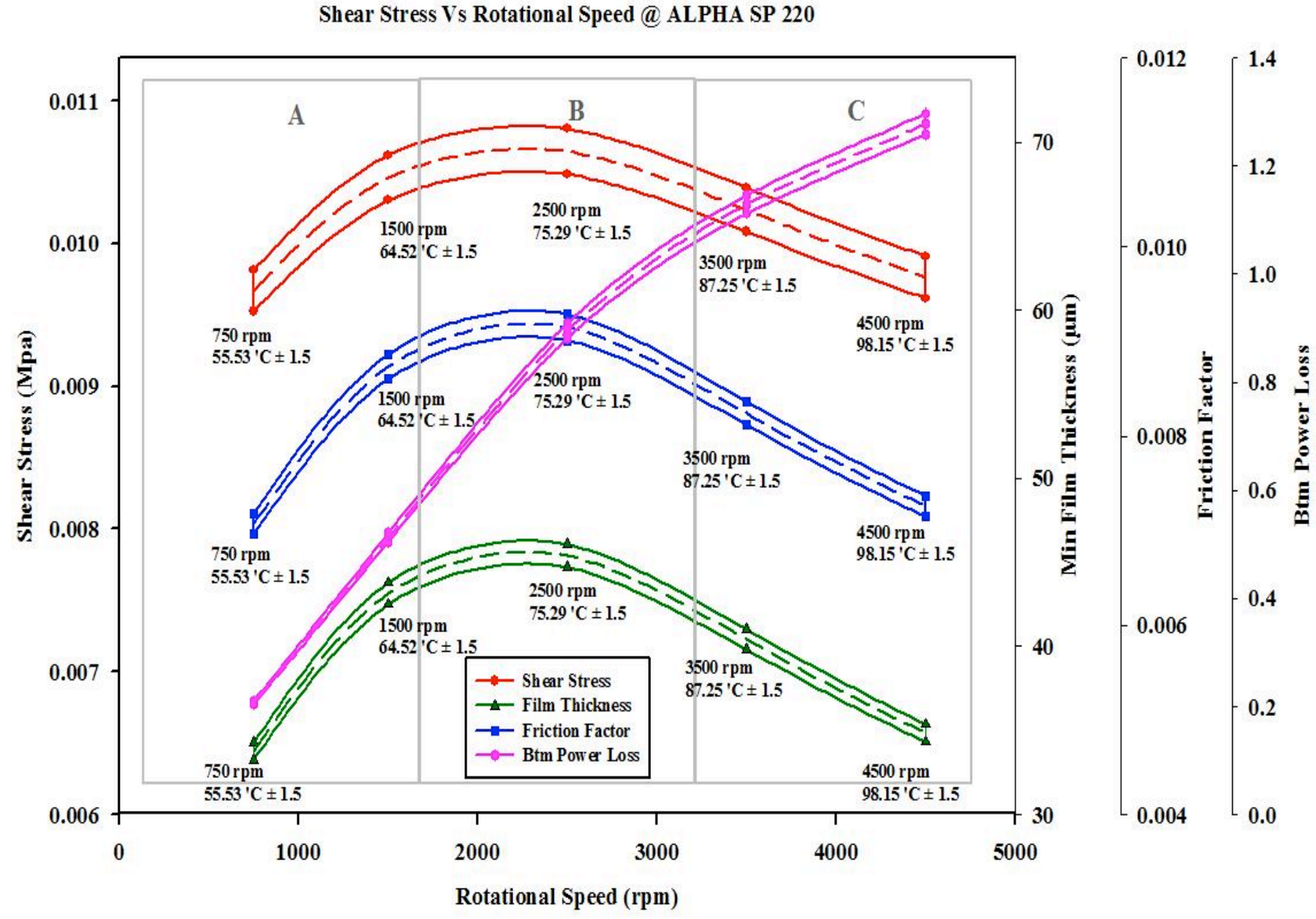

Figure 8 Shear stresses, rotational speed, dynamic viscosity (SP220), Power Loss (bottom of bearing) and minimum film thickness for load condition $10 \mathrm{kN}$ 
Of significant note in figure 8 is the relationship between rotational speed and theoretical power losses on the bottom of the journal bearing (in the region of minimum film thickness) where it is evident that power losses at the bottom of the bearing do not mirror changes in theoretical film thickness, shear stress and friction factor. Even though the friction factor reduces in value with increasing speed, the power losses increase with increasing speed. Thus it because the estimation of power losses has a direct relationship with speed and the levels of reduction in friction factor is significantly outweighed by increase in speed. This is noted in figure 9 where AE levels are seen to increase with total power losses and losses attributed to the bottom of the bearing. This was not surprising as it would be expected that AE will be generated from not only shear stress in the region of minimum film thickness but also from splashing of the oil and its motion within the top of the bearing. Therefore it is the total power losses and not the film thickness or shear stress or friction factor that is most directly correlated to the measured AE levels; a finding which hither to has not be reported. 




Figure 9 AE r.m.s, rotational speed, dynamic viscosity (SP220), bottom power losses and total loss for load condition $10 \mathrm{KN}$

Figure 10 showed that AE levels increased with increasing power losses for all three different dynamic viscosities. However at any given speed and dynamic viscosity the variation in load caused an increase in AE levels though the levels were relatively small in relation to the increase in AE levels with increasing speed. 


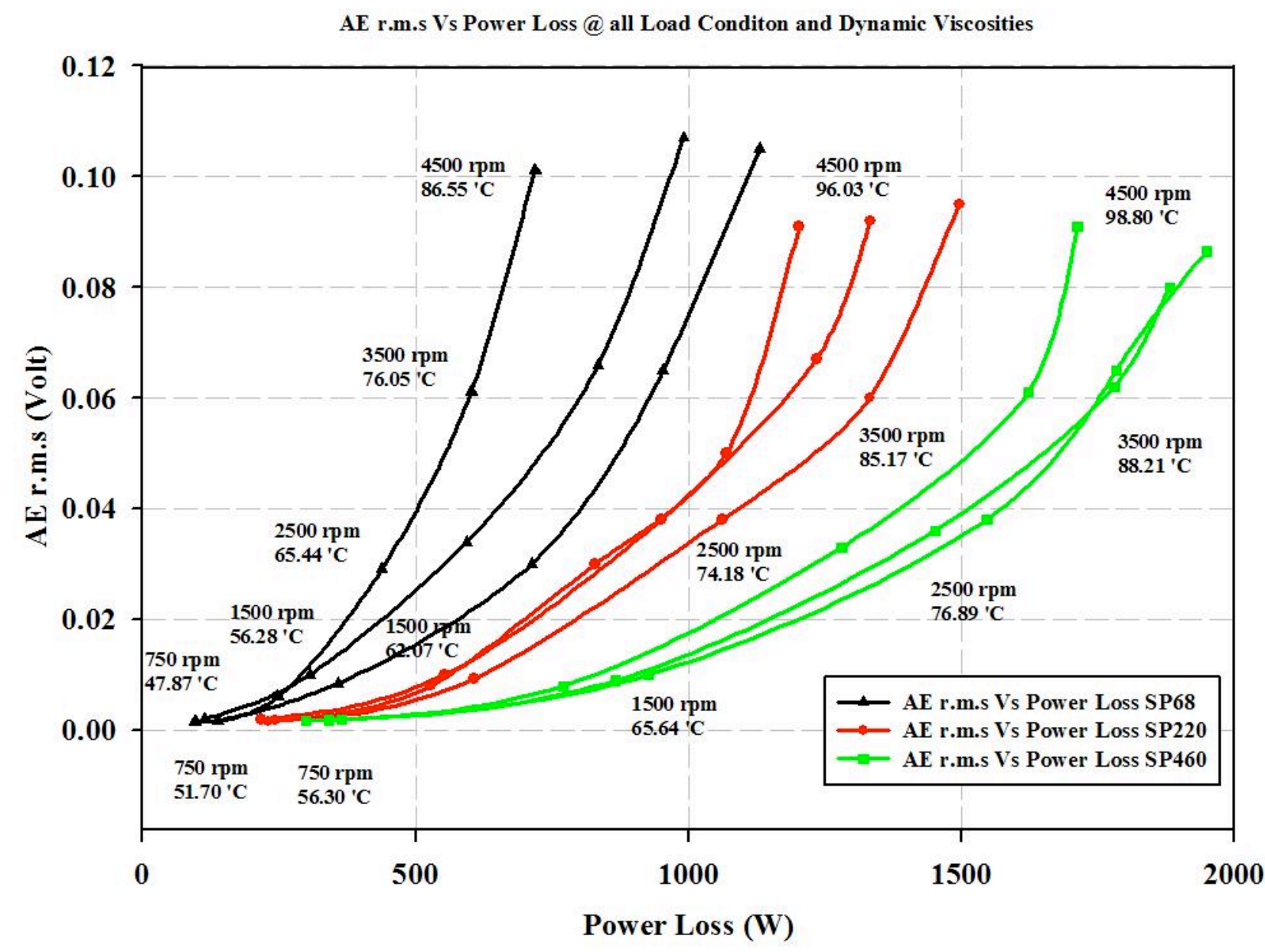

Figure 10 AE r.m.s and power loss for varying speed and load conditions $(2 \mathrm{kN}, 6 \mathrm{kN}$, $10 \mathrm{kN}$ ) at varying dynamic viscosities

\section{Conclusion}

It is evident that the Acoustic Emission (AE) technology has a great working scope in the application to hydrodynamic bearings. The observations that are presented support the author's theory that in a properly maintained hydrodynamic lubrication regime the principal source of $\mathrm{AE}$ is the friction in the shearing of the lubricant in addition to the splashing and motion of the oil within the bearing. Such a relationship will go some way in further developing the applicability of $\mathrm{AE}$ technology to monitoring rotating machinery. To date this is the first attempt at correlating AE with fluid friction and power losses in a hydrodynamic bearing. 


\section{References}

1) Vaneshette T. Henderson, “Acoustic Emission”, 2003 http://msewww.engin.umich.edu:81/people/smy/mse465_03/HENDERSON/Acoustic\%2 0Emission2.htm Accessed Nov 30, 2009

2) DROUILlARD T. F , A history of acoustic emission, Acoustic Emission Group, Los Angeles, CA, ETATS-UNIS (1982-1999) (Revue) , 1996, vol. 14, no1, pp. 1-34 (9 p.1/2)

3) Mba, D. and Rao, R.B.K.N., 2006, "Development of Acoustic Emission Technology for Condition Monitoring and Diagnosis of Rotating Machines; Bearings, Pumps, Gearboxes, Engines and Rotating Structure," The Shock and Vibration Digest, 38/1, pp 3-16.

4) Prieto, S. 2006. A Bearing Test-Rig for Extreme Operating Conditions. MsC Thesis Cranfield University, School of Mechanical Engineering.

5) J.Z. Sikorska and D. Mba' Truth, Lies acoustic emission and process machines, Journal of Mechanical Process Engineering, Part E, IMechE, Volume 222, Number 1, 1-19, 2008

6) Sato, I., (1990) "Rotating Machinery Diagnosis with Acoustic Emission Techniques", Electrical Engineering in Japan, Vol. 110, No. 2.

7) M. Leahy, D. Mba, P. Cooper, A. Montgomery, D. Owen, An experimental investigation into the capabilities of Acoustic Emission for the detection of shaft-to-seal rubbing in large power generation turbines, Journal of Engineering Tribology, Proc. Instn Mech. Engrs, Part J. 220(J7), 607 - 615, 2006.

8) M. Leahy, D. Mba, Detecting shaft-to-seal rubbing in power generation turbines with the Acoustic Emission technology, Journal of Vibration and Acoustics, ASME, Volume 128, Issue 6,798-800, 2006.

9) Mba, D., Cooke, A., Roby, D., Hewitt, G., (2004) "Detection of shaft-seal rubbing in large- scale power generation turbines with Acoustic Emissions; Case study", Journal of Power and Energy - Part A, I Mech E, Vol. 218, No. 2, pp. 71-82.

10) Hall L. D., and Mba, D., Acoustic emissions diagnosis of rotor-stator rubs using the KS statistic, Mechanical Systems and Signal Processing, Volume 18, Issue 4, Pages 849-868, 2004. 
11) Wang, Q. and Chu, F., Experimental determination of the rubbing location by means of acoustic emission and wavelet transform, Journal of Sound and Vibration, vol. 248, no. 1, pages $91-103,2001$.

12) M. Leahy, D. Mba, P. Cooper, A. Montgomery, D. Owen, Acoustic Emission technology for detection of shaft-to-seal rubbing on power generation turbines; a qualitative verification., INSIGHT, Vol. 48, no. 12, 754-755, Dec 2006.

13) Al Shaikh Mubarak, M., Mba, D., Cooper, P., Opportunities offered by acoustic emission for and blade rub detection on large scale power generation turbines. 16th International congress Condition monitoring and Diagnostic engineering management (COMADEM'2003) Vaxjo, Sweden, August 27th - 29th 2003, p 513, ISBN 91-7636376- 7.

14) Raimondi and J. Boyd "A Solution for the Finite Journal Bearing and Its Application to Analysis and Design" American Society of Lubrication Engineers, Vol. 1, No. 1, in Lubrication Science and Technology, Pergamon, New York, 1958

15) Wall shear stress calculation in ascending aorta using phase contrast magnetic resonance imaging. Investigating effective ways to calculate it in clinical practice Efstathopoulos,Efstathios P.; Patatoukas,Georgios; Pantos,Ioannis; Benekos,Odysseas; Katritsis,Demosthenes; Kelekis,Nikolaos L.:Physica Medica, 2008, 24, 4, 175-181

16) Compounding Stress Intensity Factors: Applications to Engineering Strctures Research Reports in Materials Science, Series 1, Vol 1 D. P. Rooke, Parthenon Publishing Group (November 1986), ISBN-13: 978-1850701101 


\section{Appendix A}

\begin{tabular}{|c|c|c|c|c|c|c|c|c|c|c|c|c|c|c|c|}
\hline Oil Type & P KN & Speed [RPM] & Temperature $\left({ }^{\circ} \mathrm{C}\right)$ & STDV T & $\mathrm{v}(\mathrm{cS} t)$ & $\mu\left(\mathrm{Pa}^{*} \mathrm{~s}\right)$ & S & ecc & $h \min (\mu \mathrm{m})$ & STDV hmin & Friction Factor & $\mathrm{KW} \mathrm{Btm}(\mathrm{W})$ & Total Power Loss $(\mathrm{KW})$ & Shear stresses $(M P a)$ & $\operatorname{RMS}(V)$ \\
\hline \multicolumn{16}{|l|}{ SP68 } \\
\hline & 2 & 750 & 42.64 & 2.18 & 62.06 & 0.05 & 0.13 & 0.61 & 67.05 & 3.28 & 0.0136 & 0.0800 & 0.0963 & 0.0025 & 0.002 \\
\hline & 2 & 1500 & 54.21 & 1.99 & 41.59 & 0.04 & 0.17 & 0.53 & 80.24 & 3.15 & 0.0170 & 0.1996 & 0.2474 & 0.0028 & 0.006 \\
\hline & 2 & 2500 & 66.83 & 1.25 & 26.88 & 0.02 & 0.18 & 0.51 & 83.64 & 1.99 & 0.0180 & 0.3521 & 0.4374 & 0.0029 & 0.029 \\
\hline & 2 & 3500 & 77.21 & 2.4 & 18.77 & 0.02 & 0.18 & 0.51 & 82.6 & 3.81 & 0.0177 & 0.4844 & 0.6015 & 0.0029 & 0.061 \\
\hline & 2 & 4500 & 87.17 & 1.62 & 13.3 & 0.01 & 0.16 & 0.54 & 78.32 & 2.57 & 0.0165 & 0.5800 & 0.7182 & 0.0028 & 0.101 \\
\hline Oil Type & P KN & Speed [RPM] & Temperature $\left({ }^{\circ} \mathrm{C}\right)$ & STDV T & $\mathrm{v}(\mathrm{cSt} t)$ & $\mu\left(\mathrm{Pa}^{*} \mathrm{~s}\right)$ & S & $\mathrm{ecc}$ & $h \min (\mu \mathrm{m})$ & STDV hmin & Friction Factor & $\mathrm{KW} \mathrm{Btm}(\mathrm{W})$ & Total Power Loss $(\mathrm{KW})$ & Shear stresses $(M P a)$ & $\operatorname{RMS}(V)$ \\
\hline \multicolumn{16}{|l|}{ SP68 } \\
\hline & 6 & 750 & 49.43 & 2.84 & 49.07 & 0.04 & 0.03 & 0.85 & 25.17 & 1.93 & 0.0056 & 0.0993 & 0.1140 & 0.0053 & 0.0017 \\
\hline & 6 & 1500 & 56.7 & 2.87 & 38.16 & 0.03 & 0.05 & 0.79 & 35.24 & 2.81 & 0.0073 & 0.2581 & 0.3059 & 0.0059 & 0.009 \\
\hline & 6 & 2500 & 65.15 & 2.87 & 28.48 & 0.02 & 0.06 & 0.76 & 41.58 & 3.19 & 0.0085 & 0.4962 & 0.5942 & 0.0062 & 0.03 \\
\hline & 6 & 3500 & 74.76 & 1.77 & 20.43 & 0.02 & 0.07 & 0.75 & 41.7 & 1.96 & 0.0085 & 0.6965 & 0.8343 & 0.0062 & 0.065 \\
\hline & 6 & 4500 & 85.25 & 2.81 & 14.21 & 0.01 & 0.06 & 0.77 & 38.33 & 2.93 & 0.0079 & 0.8317 & 0.9911 & 0.006 & 0.105 \\
\hline
\end{tabular}

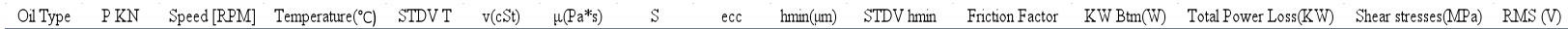
SP68

\begin{tabular}{|c|c|c|c|c|c|c|c|c|c|c|c|c|c|c|}
\hline 10 & 750 & 51.56 & 2.42 & 45.58 & 0.04 & 0.02 & 0.9 & 16.41 & 0.97 & 0.0042 & 0.1245 & 0.1386 & 0.0075 & 0.0021 \\
\hline 10 & 1500 & 57.95 & 2.63 & 36.54 & 0.03 & 0.03 & 0.86 & 23.12 & 1.65 & 0.0053 & 0.3114 & 0.3582 & 0.0086 & 0.01 \\
\hline 10 & 2500 & 64.35 & 2.36 & 29.28 & 0.03 & 0.04 & 0.83 & 28.79 & 1.79 & 0.0062 & 0.6099 & 0.7130 & 0.0092 & 0.034 \\
\hline 10 & 3500 & 76.18 & 1.43 & 19.45 & 0.02 & 0.04 & 0.84 & 27.23 & 1 & 0.0060 & 0.8185 & 0.9531 & 0.009 & 0.066 \\
\hline 10 & 4500 & 87.25 & 1.66 & 13.26 & 0.01 & 0.03 & 0.86 & 24.65 & 1.08 & 0.0056 & 0.9778 & 1.1301 & 0.0088 & 0.107 \\
\hline
\end{tabular}

\begin{tabular}{|c|c|c|c|c|c|c|c|c|c|c|c|c|c|c|c|}
\hline Oil Type & $\mathrm{PKN}$ & Speed [RPM] & Temperature $\left({ }^{\circ} \mathrm{C}\right)$ & STDV T & $v(c \mathrm{St} t)$ & $\mu\left(\mathrm{Pa}^{*} \mathrm{~s}\right)$ & S & ecc & $h \min (\mu \mathrm{m})$ & STDV hmin & Friction Factor & $\mathrm{KW} \mathrm{Btm}(\mathrm{W})$ & Total Power Loss( $(\mathrm{KW})$ & Shear stresses $(\mathrm{MPa})$ & $\operatorname{RMS}(V)$ \\
\hline \multicolumn{16}{|l|}{ SP220 } \\
\hline & 2 & 750 & 45.42 & 2.39 & 176.08 & 0.16 & 0.37 & 0.33 & 113.36 & 3.57 & 0.0318 & 0.1869 & 0.2303 & 0.0044 & 0.002 \\
\hline & 2 & 1500 & 58.53 & 3.59 & 102.75 & 0.09 & 0.44 & 0.3 & 118.74 & 5.14 & 0.0364 & 0.4277 & 0.5281 & 0.0049 & 0.008 \\
\hline & 2 & 2500 & 72.6 & 2.7 & 57.64 & 0.05 & 0.41 & 0.32 & 116.43 & 3.9 & 0.0343 & 0.6718 & 0.8288 & 0.0046 & 0.03 \\
\hline & 2 & 3500 & 83.04 & 2.47 & 37.54 & 0.03 & 0.37 & 0.33 & 113.18 & 3.63 & 0.0317 & 0.8684 & 1.0697 & 0.0043 & 0.05 \\
\hline & 2 & 4500 & 92.96 & 1.75 & 24.97 & 0.02 & 0.32 & 0.37 & 107.37 & 2.75 & 0.0278 & 0.9792 & 1.2028 & 0.0039 & 0.091 \\
\hline
\end{tabular}

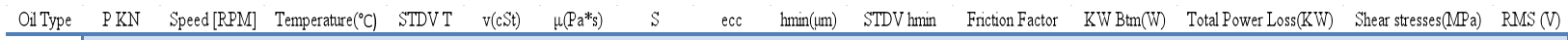
SP220

\begin{tabular}{|l|l|l|l|l|l|l|l|l|l|l|l|l|l|l|l|}
\hline 6 & 750 & 54.15 & 2.66 & 123.01 & 0.11 & 0.09 & 0.7 & 51.6 & 4.09 & 0.0103 & 0.1822 & 0.2171 & 0.0067 \\
\hline 6 & 1500 & 63.17 & 2.97 & 84.92 & 0.08 & 0.12 & 0.62 & 64.55 & 5.15 & 0.0131 & 0.4601 & 0.5529 \\
\hline 6 & 2500 & 74.65 & 3.82 & 52.99 & 0.05 & 0.12 & 0.61 & 66.24 & 6.74 & 0.0134 & 0.7894 & 0.9495 & 0.0074 \\
\hline 6 & 3500 & 85.21 & 1.9 & 34.34 & 0.03 & 0.11 & 0.63 & 62.08 & 3.24 & 0.0125 & 1.0286 & 1.2343 \\
\hline 6 & 4500 & 96.98 & 1.46 & 21.17 & 0.02 & 0.09 & 0.69 & 52.8 & 2.28 & 0.0106 & 1.1182 & 0.01 & 1.3337 \\
\hline
\end{tabular}

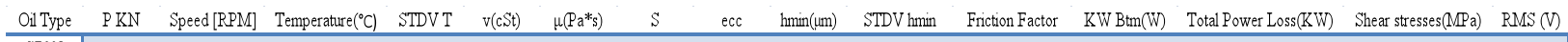
SP220

\begin{tabular}{|c|c|c|c|c|c|c|c|c|c|c|c|c|c|c|}
\hline 10 & 750 & 55.53 & 2.28 & 116.23 & 0.1 & 0.05 & 0.8 & 33.76 & 2.49 & 0.0071 & 0.2076 & 0.2426 & 0.0097 & 0.0018 \\
\hline 10 & 1500 & 64.52 & 2.21 & 80.34 & 0.07 & 0.07 & 0.75 & 43.14 & 2.86 & 0.0087 & 0.5129 & 0.6066 & 0.0105 & 0.009 \\
\hline 10 & 2500 & 75.29 & 2.9 & 51.61 & 0.05 & 0.07 & 0.73 & 45.39 & 4.01 & 0.0092 & 0.8956 & 1.0616 & 0.0106 & 0.038 \\
\hline 10 & 3500 & 87.25 & 1.45 & 31.57 & 0.03 & 0.06 & 0.76 & 40.43 & 1.78 & 0.0082 & 1.1293 & 1.3316 & 0.0102 & 0.06 \\
\hline 10 & 4500 & 98.15 & 2.42 & 20.18 & 0.02 & 0.05 & 0.8 & 34.83 & 2.59 & 0.0073 & 1.2781 & 1.4960 & 0.0098 & 0.095 \\
\hline
\end{tabular}

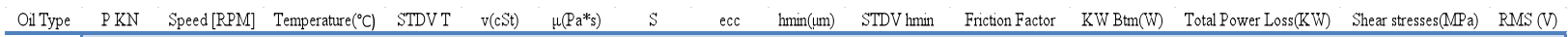

\begin{tabular}{|c|c|c|c|c|c|c|c|c|c|c|c|c|c|c|c|}
\hline \multicolumn{16}{|l|}{ SP 460} \\
\hline & 2 & 750 & 54.92 & 1.02 & 234.27 & 0.21 & 0.5 & 0.27 & 123.44 & 1.64 & 0.0412 & 0.2421 & 0.2991 & 0.0054 & 0.002 \\
\hline & 2 & 1500 & 64.84 & 0.91 & 149.58 & 0.13 & 0.64 & 0.22 & 132.87 & 1.79 & 0.0521 & 0.6114 & 0.7711 & 0.0064 & 0.008 \\
\hline & 2 & 2500 & 76.22 & 1.7 & 89.41 & 0.08 & 0.64 & 0.22 & 132.7 & 3.38 & 0.0519 & 1.0152 & 1.2804 & 0.0063 & 0.033 \\
\hline & 2 & 3500 & 86 & 2.66 & 57.45 & 0.05 & 0.57 & 0.24 & 128.38 & 4.37 & 0.0468 & 1.2825 & 1.6224 & 0.0059 & 0.061 \\
\hline & 2 & 4500 & 96.29 & 2.67 & 36.07 & 0.03 & 0.46 & 0.29 & 120.7 & 4.2 & 0.0384 & 1.3509 & 1.7125 & 0.0051 & 0.091 \\
\hline
\end{tabular}

\begin{tabular}{|c|c|c|c|c|c|c|c|c|c|c|c|c|c|c|c|}
\hline Oil Type & P KN & Speed [RPM] & Temperature $\left({ }^{\circ} \mathrm{C}\right)$ & STDV T & $\mathrm{v}(\mathrm{cSt})$ & $\mu\left(\mathrm{Pa}^{*} \mathrm{~s}\right)$ & S & ecc & $h \min (\mu \mathrm{m})$ & STDV hmin & Friction Factor & $\mathrm{KW} \mathrm{Btm}(\mathrm{W})$ & Total Power Loss (KW) & Shear stresses $(\mathrm{MPa})$ & $\operatorname{RMS}(\mathrm{V})$ \\
\hline \multicolumn{16}{|l|}{ SP 460} \\
\hline & 6 & 750 & 56.2 & 0.67 & 221.09 & 0.2 & 0.16 & 0.55 & 76.51 & 1.37 & 0.0160 & 0.2814 & 0.3403 & 0.0082 & 0.0019 \\
\hline & 6 & 1500 & 65.44 & 1.65 & 145.58 & 0.13 & 0.21 & 0.48 & 89.12 & 3.37 & 0.0197 & 0.6952 & 0.8666 & 0.0092 & 0.009 \\
\hline & 6 & 2500 & 76.6 & 1.74 & 87.88 & 0.08 & 0.21 & 0.47 & 89.4 & 3.54 & 0.0198 & 1.1642 & 1.4515 & 0.0092 & 0.036 \\
\hline & 6 & 3500 & 87.7 & 2.3 & 53.2 & 0.05 & 0.18 & 0.52 & 81.82 & 4.77 & 0.0175 & 1.4344 & 1.7801 & 0.0086 & 0.062 \\
\hline & 6 & 4500 & 98.77 & 1.53 & 32.24 & 0.03 & 0.14 & 0.59 & 70.49 & 3.09 & 0.0145 & 1.5269 & 1.8809 & 0.0077 & 0.08 \\
\hline
\end{tabular}

\begin{tabular}{|c|c|c|c|c|c|c|c|c|c|c|c|c|c|c|c|}
\hline Oil Type & P KN & Speed [RPM] & Temperature $\left({ }^{\circ} \mathrm{C}\right)$ & STDV T & $\mathrm{v}(\mathrm{cSt})$ & $\mu\left(\mathrm{Pa}^{*} \mathrm{~s}\right)$ & S & ecc & $h \min (\mu \mathrm{m})$ & STDV hmin & Friction Factor & $\mathrm{KW} \mathrm{Btm}(\mathrm{W})$ & Total Power Loss (KW) & Shear stresses $(\mathrm{MPa})$ & $\operatorname{RMS}(V)$ \\
\hline \multicolumn{16}{|l|}{ SP 460} \\
\hline & 10 & 750 & 57.78 & 0.63 & 205.85 & 0.19 & 0.09 & 0.69 & 51.96 & 1.08 & 0.0104 & 0.3057 & 0.3644 & 0.0112 & 0.002 \\
\hline & 10 & 1500 & 66.62 & 2.07 & 138.01 & 0.12 & 0.12 & 0.63 & 63.71 & 4.03 & 0.0129 & 0.7558 & 0.9264 & 0.0122 & 0.01 \\
\hline & 10 & 2500 & 77.87 & 2.28 & 82.98 & 0.07 & 0.12 & 0.62 & 63.8 & 4.44 & 0.0129 & 1.2616 & 1.5464 & 0.0122 & 0.038 \\
\hline & 10 & 3500 & 90.94 & 2.64 & 45.95 & 0.04 & 0.09 & 0.69 & 53.5 & 4.68 & 0.0107 & 1.4685 & 1.7838 & 0.0113 & 0.065 \\
\hline & 10 & 4500 & 101.35 & 3.48 & 28.69 & 0.03 & 0.07 & 0.73 & 45.6 & 5.25 & 0.0092 & 1.6191 & 1.9496 & 0.0107 & 0.087 \\
\hline
\end{tabular}

